\title{
A Systematic Review and Meta-analysis on the Factors Related to Post-traumatic Growth of Fire Officials
}

\author{
Myung-Gwan Kim', Seung-Woo Han² \\ ${ }^{1}$ Researcher, Graduate School of Public Health, Kyungpook National University, Daegu; ${ }^{2}$ Professor, Department of Emergency Medical Technology, \\ Kyungil University, Gyeongsan, Korea
}

Objectives: The present study is a meta-analysis mainly based on previous papers analyzing factors related to post-traumatic growth of fire officials. Methods: Using open source statistical software, R (3.6.0), the final 14 selected papers carried out an effect-size meta-analysis using correlation coefficient. It was conducted with 4 foreign and 4 domestic search engines. Foreign search engines are the following: EMBASE, CINAHL, PubMed, and Cochrane Library. On the other hand, Korean search engines are the following: KISS, RISS, NDSL and KMbase. Results: Research shows that, for internal-factors, the effect size between post-traumatic growth and self-elasticity was $r=0.37$, with resilient elasticity was $r=0.34$, and with self-esteem was $r=0.32$. For external-factors, the effect size between post-traumatic growth and sense calling was $r=0.50$, and with career calling was $r=0.25$. For coping-mechanism, the effect size between post-traumatic growth and social support was $r=0.36$, and with self-disclosure was $r=0.20$. For coping-strategy, the effect size between post-traumatic growth and problem-focused coping was $r=0.49$ and with intentional rumination was $r=0.54$. Lastly, for traumatic-experiences, the effect size between post-traumatic growth and PTSD was $r=0.23$. Conclusions: Therefore, this study would like to develop strategies promoting intentional rumination and provide the basis for the mental nursing arbitration program.

Key words: Traumatic, Growth, Meta-analysis, Fire officials, Systematic review

\section{INTRODUCTION}

Due to the recent global warming and industrialization, natural and social disasters are rapidly increasing, and its scale and loss of property are also getting bigger. In particular, fire officials play a pivotal role in the frontline of these disaster sites and are responsible for the lives and safety of the people at dangerous sites. They may experience a variety of traumatic experiences due to the 24-hour unexpected and unpredictable working environment, leading to health threats and post-traumatic stress disorder (PTSD)[1].

From a national perspective, systematic preventive approach enhancing the mental health of fire officers is considered important as their various traumatic experiences and accompanying post-traumatic stress

Corresponding author: Seung-Woo Han

50 Gamasil-gil, Hayang-eup, Gyeongsan 38428, Korea

E-mail:woowo01200@naver.com

Received: October 10, 2020 Revised: November 17, 2020 Accepted: November 23, 2020

No potential conflict of interest relevant to this article was reported. disorder could have an important impact on the safety of the community beyond the level of physical and psychological pain of an individual, and furthermore on the lives of the people. Accordingly, agencies responsible for mental health in each country, including the World Health Organization (WHO), have shown interest in cognitive behavior reducing PTSD and in various therapeutic interventions reducing its symptoms [2].

In the past, it has been pointed out that treatment and pathological models reducing symptoms were focusing only on causes and treatments for symptoms and recovering until the pre-existing condition [3]. However, post-traumatic growth (PTG) has recently emerged positive psychology, such as quality of life and well-being of individuals, was focused and internal adaptability and its direction are considered an important part of treatment beyond the functional level of trauma transfer [4].

How to cite this article:

Kim MG, Han SW. A systematic review and meta-analysis on the factors related to post-traumatic growth of fire officials. J Health Info Stat 2020;45(4):373-384. Doi: https://doi.org/10.21032/ jhis.2020.45.4.373

(C) It is identical to the Creative Commons Attribution Non-Commercial License (https://creativecommons.org/licenses/by-nc/4.0) which permit sunrestricted non-commercial use, distribution, and reproduction in any medium, provided the original work is properly cited.

(c) 2020 Journal of Health Informatics and Statistics 
Post-traumatic growth refers to positive psychological changes perceived to restore the functional level and promote healthy life changes after experiencing fatal trauma that could pose a threat to an individual's life [5]. Calhoun and Tedeschi [5], firstly presented the concept of posttraumatic growth, noted that these positive psychological changes should be approached from a variety of therapeutic perspectives, away from the perspective of treating symptoms focused on past diseases. They stated individuals having trauma experience a variety of positive internal processes to positively recognize and overcome trauma becoming post-traumatic growth rather than post-traumatic stress [6].

In a post-traumatic growth model developed by Calhoun and Tedeschi [5], if an individual with various characteristics (personality characteristics, demographic and sociological characteristics) experiences fatal trauma enough to threaten their lives, one's beliefs may be challenged leading to severe pain. At this time, the individual tried to relieve the pain by using coping mechanisms such as social support and self-exposure to escape the pain situation. Through this response, suffering individuals experience post-traumatic growth by intentional rumination as one try to reflect on positive meaning of the traumatic experience, and reorganizes the meaning of life.

Recently, studies have been conducted on post-traumatic growth based on various subjects and theoretical evidence. In papers regarding factors promoting post-traumatic growth, general positive factors were social support [7] and coping ability [8], and general negative factor was PTSD [9]. However, studies of post-traumatic growth were mostly focused on certain diseases, such as liver transplant patients [10], cancer patients [11], and parents of children with diseases [12], and post-traumatic growth for high-risk professions experiencing actual trauma is very insufficient.

Therefore, the present study aims to systematically examine and metaanalyze the factors promoting post-traumatic growth of fire officials, focusing on related previous papers, and thereby computing the effect size and explorate various related factors to find evidence and effective nursing interventions strategies contributing to the development of the program.

\section{METHODS}

\section{Study design}

The present study is a systematic literature review and meta-analysis study focusing on previous papers to analyze factors related to post-trau- matic growth of fire officials.

\section{Inclusion and exclusion criteria}

The core question of this paper consists of 'What are the factors related to post-traumatic growth of fire officials?' The subject of the present study is a correlation survey study on the factors related to post-traumatic growth of fire officials.

(1) In PICO, Inclusions were papers researched on fire officials, (2) presented the late post-traumatic growth by fire officials, (3) published after 2010, (4) researched on correlation. The criteria for exclusion were (1) papers not clearly mentioned fire officials (e.g., emergency medical personnel, emergency medical technician), (2) pre-2010 papers, (3) not clearly presented in English 4) academic presentation materials.

\section{Data collection and sampling}

The data search was carried out by two researchers regarding papers from January 1, 2011 to April 30, 2020 and aimed at analyzing variables related to post-traumatic growth of fire officials.

Four foreign search engines and four domestic search engines were implemented.

Excerpta Medica database (EMBASE), Cumulative Indexing Nursing \& Allied Health Literature (CINAHL), PubMed, and Cochrane Library were used for foreign search engines. On the other hand, Korean studies Information Service System (KISS), Research Information Sharing Service (RISS), National Digital Science Library (NDSL), and Korean Medical Database (KMbase) were used for Korean search engines.

The search was conducted using the Medical Subject Heading (MeSH) and the Biomedical term index EMBASE TREE [EMTREE]. As main search terms, 'Firefighter', 'Firefighter', 'Firefighter', 'Trauma', 'Post Trauma', 'Growth', and 'Post Trauma Growth' were used and each were connected with AND/OR.

For data collection and screening, two researchers carefully examined papers that fit the purpose of the study. All studies continued until consistent consensus was reached through independent review and cross-reviewing. The selected papers were listed and the duplicate literatures were removed using EndNote X8. After eliminating duplicate literatures, title and abstract were fully reviewed to select papers fitting literature selection and exclusion criteria. Based on its full research paper, final literatures were selected whether papers studied the cause of post-traumatic growth of fire officials. The author, year, sample size, demographic anal- 
ysis (age, gender), post-traumatic growth tool, related factors, and total score of finally selected papers are recorded on the coding table.

\section{Quality evaluation of literature}

This paper analyzed the quality evaluation of literature using the 'Quality Assessment and Validity Tool for Correlational Studies' used in the research of Estabrookes, Wong and Cummings, focusing on the preceding papers regarding the factors related to post-traumatic growth of fire officials. The tool consisted of four items, 'Research Design', 'Sample', 'Messure', and 'Statistical Analysis', and each question was rated as a 1 for 'Yes' and 0 for 'No'. The resulting totals were categorized as 0 to 4 points for low quality of literature, 5 to 9 points for medium, and 10 to 13 points for high level. For the quality evaluation, two researchers independently conducted and recorded their results via Kappa coefficient: 1 if both agreed and 0 if not. The results of the present study showed that $92 \%$ agreement was reached. To fulfill the remaining $8 \%$, final selection was reviewed and completed with $100 \%$. The results of the quality evaluation of the literature in this study determined that the 14 selected papers in this study were all five points or more.

\section{Data analysis}

The finally selected papers carried out an effect-size meta-analysis using correlation coefficients through open source statistical software $\mathrm{R}$ (3.6.0). The author, year, sample size, demographic analysis (age, gender), post-traumatic growth tools, related factors, and total score were compiled in the coding table and analyzed by number and percentage. In order to identify factors related to the post-traumatic growth of fire officials, all statistically significant variables in each paper were compiled and recorded. The analyzed paper was selected if it presented a correlation coefficient for post-traumatic growth. The effect size analysis criteria were derived from the correlation classification criteria in Cohen [13]. In the present study, if the absolute value of effect size was below 10 , it was analyzed as small effect size, if absolute value was 0.25 as medium effect size, and 0.40 or higher was considered large effect size. Confidence interval (CI) of the effect size generally assumes 95\% and, if CI does not include " 0 " within the upper and lower range, the $p$ value is less than 0.05 , meaning that the effect size is statistically significant.

Inconsistent differences in effect sizes between studies are called heterogeneity[14]. $\mathrm{I}^{2}$, an index representing the heterogeneity of the effect size, represents the actual proportion of the total variance and generally interprets $I^{2}$ as less heterogeneity, less than $50 \%$ as moderate, and $50 \%$ or more as high heterogeneity [15]. Meanwhile, to verify the heterogeneity of the effect size, the $Q$ value was set to confirm the observed variance of each effect size. This indicates that if the $\mathrm{Q}$ value represents a significant value in the $\mathrm{P}$ value, then the null hypothesis for homogeneity is rejected and therefore not from the same population [16]. Therefore, in the present study, assuming the heterogeneity of selected papers, a random effect model will be applied to extract the effect size, 95\% confidence interval, $\mathrm{I}^{2}$, and $\mathrm{Q}$ value of each variable.

Publication bias measures errors in which research results cannot be published due to its direction. The Trim-and-Fill method was used in the present study to estimate whether Publication bias affects the results, determining how much the error affects the results of the study, reexamining the errors and determining if there is a publication bias [17].

\section{RESULTS}

\section{Search results}

The final selection were 14 papers presenting correlations. A total of 1,340 papers were searched. EMBASE $(n=247)$, CINAHL $(n=380)$, PubMed ( $n=156)$, and Cochrane Library $(n=148)$ were searched in foreign papers. On the other hand, KISS ( $n=26)$, RISS ( $n=193)$, NDSL ( $n=$

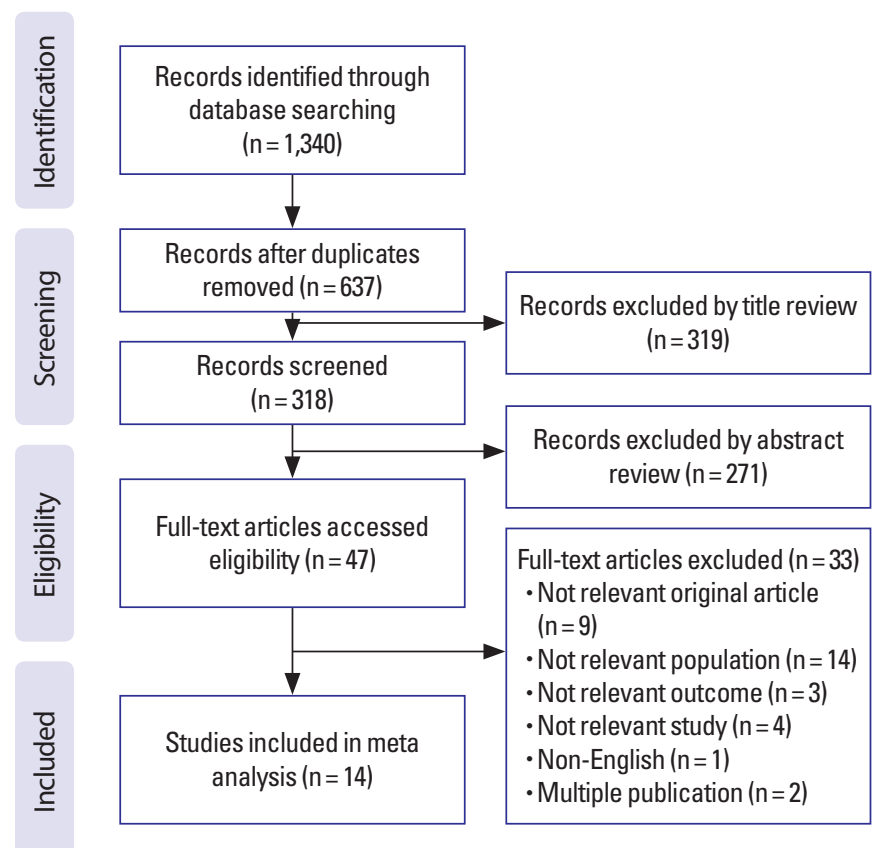

Figure 1. Flow chart of the sample selection process. 
112), and KMbase ( $\mathrm{n}=78)$ were searched in Korean papers. Of the 1,340 papers, 703 were removed due to duplication, and 319 due to its title. Of the remaining 318 papers, 271 papers were removed by reviewing abstracts of the papers. With the last 47 remaining papers, the two researchers independently performed research based on inclusion criteria. Specifically, a total of 33 papers were removed: 9 with publication format in exclusion criteria, 14 with subject in exclusion criteria, 3 with outcome variables that were not post-traumatic growth, 4 with research design not meeting the purpose of the present study, 1 with not in English (The text was in Japanese), and 2 with multiple publication. The final selection of paper was reviewed based on its full research paper, and the final 14 papers were selected with agreement (Figure 1).

\section{Sample characteristics}

The final selection of 14 papers are all correlative research studies. All papers were recently published within the last 10 years from 2011 to 2020: total of four (A2, A9, A10, A12) prior to 2015 and six (A1, A3-8, A11, A13-14) since 2015. Of these, a total of four papers (A4, A7-8) were identified as 2020 publications. In demographic characteristics, most of the papers showed a wide distribution of age ranging from $20 \mathrm{~s}$ to $50 \mathrm{~s}$ and 60s, and in three papers (A12-14), it studied fire officials without age limit, over 18-20. With work characteristics of fire officials, male accounted mostly. Most papers showed that male accounted for $90 \%$ of the population, one paper studied $100 \%$ in male (A9), and one (A13) without mentioning thegender. All 14 papers studied fire officials and none of

Table 1. Sample characteristics $(n=14)$

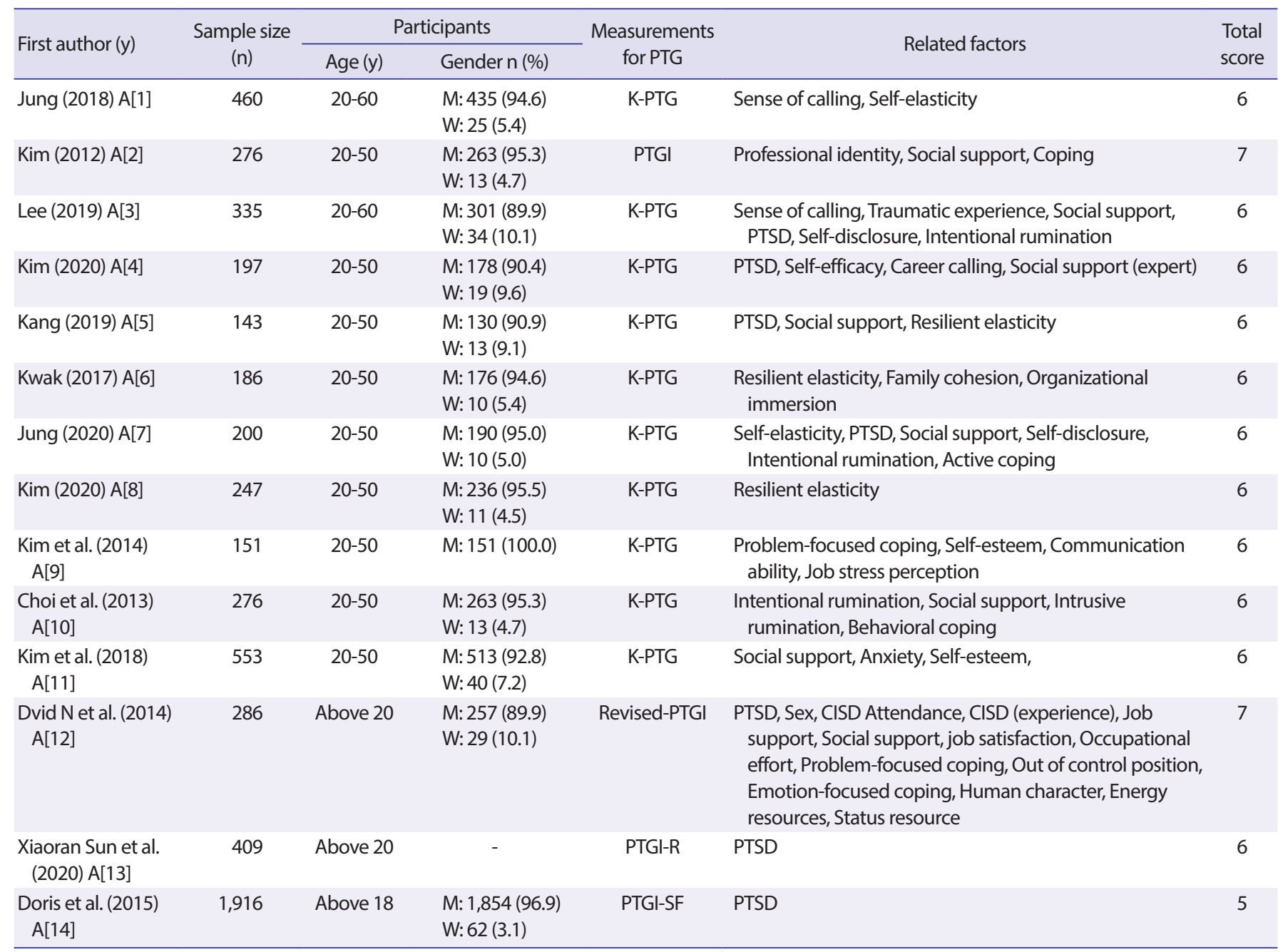

M, men; W, women; PTG, post-traumatic growth; K-PTG, Korean version of post-traumatic growth inventory; PTGI, post-traumatic growth inventory; PTGI$\mathrm{R}$, revised Chinese version of the post-traumatic growth inventory; PTGI-SF, short form of the post-traumatic growth inventory; PTSD, post-traumatic stress disorder; CISD, critical incident stress debriefing. 
them included emergency medical personnel and emergency medical technician (Table 1).

\section{Sample size}

Fourteen selected papers consist of at least 100 samples, and the papers (A5) studied with the smallest number of samples were identified as 143. All papers met criteria of quantitative studies, consisting at least 30 samples. Meanwhile, the paper (A14), studied the largest number of samples, was identified as a total of 1,916 .

\section{Factors related to post-traumatic growth of fire officials}

Of the 14 selected papers, a total of 55 were post-traumatic growth-related factors. Based on the post-traumatic growth model developed by Calhoun and Tedeschi [5], we classified the personality characteristics before trauma as internal factors and the demographic and sociological characteristics associated with the job as external factors, taking into account the various characteristics (personality and demographic characteristics). In the present study, internal factors related to post-traumatic growth are Self-elasticity, Resilient Elasticity and Self-esteem, and external factors are Sense of Calling and Career Calling. Psychological pain caused by trauma experience was classified as PTSD, and Coping-mechanisms escaping these pain situations are Social support and Self-disclosure. Finally, the Coping-strategy attempts to redefine existing values by positively interpreting the trauma experience and re-structured the meaning of life are Intentional rumination and Problem-focused coding. This paper tries to systematically consider factors related to post-traumatic growth of fire officials based on its model developed by Calhoun and Tedeschi [5] (Figure 2).

\section{Instruments}

Of the 14 selected papers, 10 out of 11 Korean papers used Korean version of Post-traumatic Growth Inventory (K-PTGI) developed by Tedeschi and Calhoun [6] and modified and supplemented by Song [17]. The circle scale consists of a total of 5 factors (change of interpersonal relationship, change of self-awareness, change of philosophy of life, change of spirituality, and appreciation of life) 21 questions, and 6 point Likert scale. On the other hand, the K-PTGI, modified and supplemented by Song [18], consists of 4 factors (change of self-awareness, discovery of new possibilities, increased interpersonal depth, and change of spirituality), 16 questions, and 6 point Likert scale. It consists of points from zero "I have not experienced the change" to five "I have experienced the change very much", and higher could be interpreted as more post-traumatic growth experienced. One paper (A2) used the original circle tool but three foreign papers (A12, 13, and 14) confirmed using tools adapted to the demographic characteristics. The first (A14) used tools modified and supplemented by Cann et al. [19], studied post-traumatic growth for fire officials from eight European Allies. This tool, a short form of the Post-traumatic Growth Inventory (PTGI-SF), measures positive results changed from chronic trauma, consisting of a total of 10 questions on 6 point Likert scale. The second used a modified and supplemented tool from China (PTGI-R)[20] with a total of 22 questions and 6 point Likert scale. This tool consists of five points, from zero 'I haven't experienced post-traumatic growth' to five 'I have experienced post-traumatic growth very much' and higher could be interpreted as more post-traumatic growth experienced. Lastly, the third modified and supplemented tool measuring post-traumatic growth with a total of eight questions, two questions on the circle scale and the six questions used by Sattler et. Al [21], con-

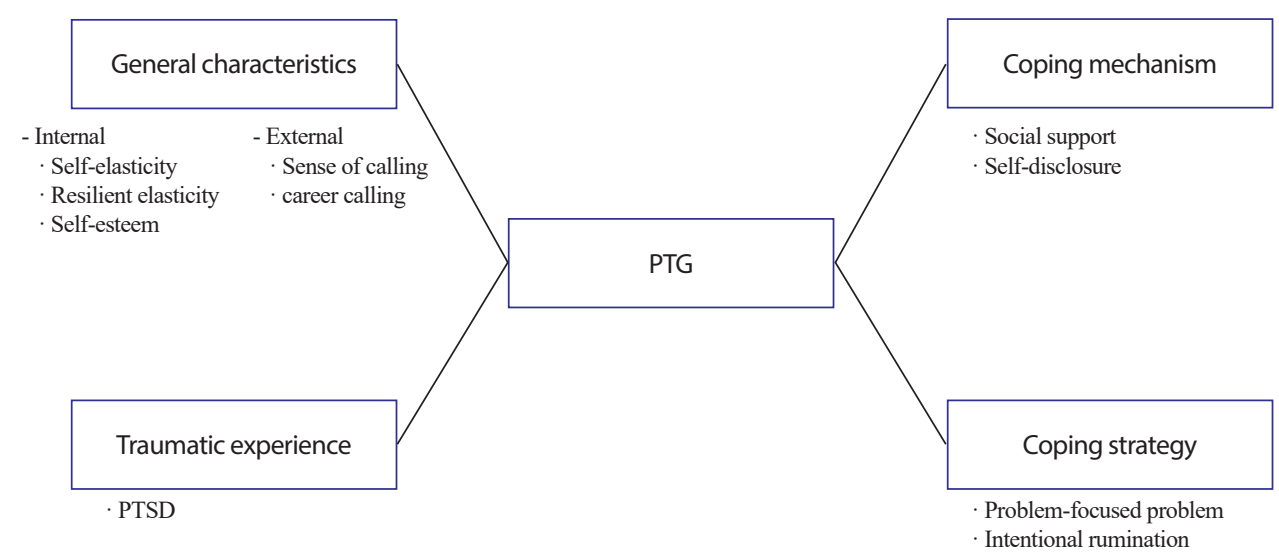

Figure 2. Schematic diagram of factors related to PTG for fire officials. PTG, post-traumatic growth; PTSD, post-traumatic stress disorder. 
sists of seven points from one "symbolically decreased post-traumatic growth" to seven "symbolically increased post-traumatic growth."

\section{Meta-analytical results}

\section{Internal factor}

Internal factors were analyzed with self-elasticity, Resilient elasticity, and self-esteem. The effect size between self-elasticity and post-traumatic growth was $r=0.37$ (95\% confidence interval, $95 \% \mathrm{CI}=0.18$ to 0.53$), \mathrm{z}=$ $3.79, p<0.001$ showing significant relationship. The effect size between Resilient elasticity and post-traumatic growth was $r=0.32(95 \% \mathrm{CI}=0.25$ to 0.38$), \mathrm{z}=8.66, p<0.001$ showing significant relationship. Combining self-elasticity, Resilient elasticity, and self-testeem as internal factors, the effect size was $r=0.34$ ( $95 \% \mathrm{CI}=0.28$ to 0.41$), \mathrm{z}=9.54, p<0.001$ showing significant relationship between internal factors and post-traumatic growth. The effect size is based on the criteria set forth by Cohen: below 0.20 were very small effect sizes; 0.20 - 0.50 were small effect sizes; 0.50 0.80 were medium effect size, and 0.80 or above were large effect sizes. In addition, the effect size was interpreted as statistically significant if the 95\% CI did not include zero [22].

\section{External factor}

External factors were analyzed with Sense of Calling and Career Calling. The effect size between Sense of Calling and post-traumatic growth was $\mathrm{r}=0.50(95 \% \mathrm{CI}=0.25$ to 0.69$) \mathrm{z}=3.62, p<0.001$ showing significant relationship. The effect size between Career calling and post-traumatic growth was $\mathrm{r}=0.25$ (95\% $\mathrm{CI}=0.19$ to 37$), \mathrm{z}=5.85, p<0.001$ showing significant relationship. Combining Sense of Calling and Career Calling as external factors, effect size was $r=0.40(95 \% \mathrm{CI}=0.31$ to 0.56$), \mathrm{z}=3.93$, $p<0.001$, showing significant relationship between external factors and post-traumatic growth.

\section{Coping mechanism}

Coping mechanisms were analyzed with social support, and self-disclosure. The effect size between social support and post-traumatic growth was $\mathrm{r}=0.36(95 \% \mathrm{CI}=0.22$ to 0.49$) \mathrm{z}=4.81, p=0.001$ showing significant relationship. The effect size between Self-disclosure and posttraumatic growth was $\mathrm{r}=0.20(95 \% \mathrm{CI}=0.06$ to 0.34$), \mathrm{z}=4.81, p=0.005$ showing significant relationship. Combining social support and self-discovery as Coping mechanisms, the effect size was $r=0.35$ (95\% CI $=0.27$ to 0.42$), z=7.92, p<0.001$, showing significant relationship between coping mechanisms and post-traumatic growth.

\section{Coping strategy}

Coping-strategies were analyzed with problem-focused coping and Intentional rumination. The effect size between problem-focused coping and post-traumatic growth was $\mathrm{r}=0.49(95 \% \mathrm{CI}=0.26$ to 0.67$), \mathrm{z}=3.87$, $p<0.001$ showing significant relationship. The effect size between Intentional rumination and post-traumatic growth was $\mathrm{r}=0.54(95 \% \mathrm{CI}=0.44$

Table 2. Effect size of factors related to PTG

\begin{tabular}{|c|c|c|c|c|c|c|c|c|c|c|c|}
\hline \multirow{2}{*}{ Variables } & \multirow{2}{*}{ Categories } & \multirow{2}{*}{$\mathrm{K}$} & \multirow{2}{*}{$\mathrm{n}$} & \multirow{2}{*}{$\begin{array}{c}\text { Effect size } \\
(r)\end{array}$} & \multirow{2}{*}{$95 \% \mathrm{Cl}$} & \multirow{2}{*}{ z } & \multirow{2}{*}{$p$} & \multicolumn{4}{|c|}{ Heterogeneity } \\
\hline & & & & & & & & $\mathrm{Tau}^{2}$ & Q & $\mathrm{I}^{2}(\%)$ & $p$ \\
\hline \multirow{4}{*}{$\begin{array}{l}\text { Internal- } \\
\text { factor }\end{array}$} & Self-elasticity & 2 & 660 & 0.37 & $0.18-0.53$ & 3.79 & $<0.001$ & 0.017 & 5.73 & 82.6 & 0.017 \\
\hline & Resilient elasticity & 3 & 576 & 0.34 & $0.21-0.46$ & 4.97 & $<0.001$ & 0.010 & 5.66 & 64.7 & 0.059 \\
\hline & Self-esteem & 2 & 704 & 0.32 & $0.25-0.38$ & 8.66 & $<0.001$ & 0.000 & 0.49 & 0.0 & 0.484 \\
\hline & Total & 7 & 1,940 & 0.34 & $0.28-0.41$ & 0.95 & $<0.001$ & 0.006 & 14.72 & 59.0 & 0.020 \\
\hline \multirow{3}{*}{$\begin{array}{l}\text { External- } \\
\text { factor }\end{array}$} & Sense of calling & 2 & 795 & 0.50 & $0.25-0.69$ & 3.62 & $<0.001$ & 0.043 & 17.54 & 94.3 & $<0.001$ \\
\hline & Career calling & 1 & 197 & 0.28 & $0.19-0.37$ & 5.85 & $<0.001$ & 0.000 & 0.02 & 0.0 & 0.658 \\
\hline & Total & 3 & 992 & 0.44 & $0.23-0.61$ & 3.93 & $<0.001$ & 0.042 & 39.57 & 93.0 & $<0.001$ \\
\hline \multirow{3}{*}{$\begin{array}{l}\text { Coping- } \\
\text { mechanism }\end{array}$} & Social support & 4 & 1,258 & 0.36 & $0.22-0.48$ & 4.81 & 0.001 & 0.021 & 20.66 & 85.5 & $<0.001$ \\
\hline & Self-disclosure & 2 & 535 & 0.20 & $0.06-0.34$ & 2.81 & 0.005 & 0.007 & 2.70 & 63.0 & 0.100 \\
\hline & Total & 6 & 1,793 & 0.33 & $0.24-0.42$ & 7.92 & $<0.001$ & 0.011 & 24.20 & 77.0 & $<0.001$ \\
\hline \multirow{3}{*}{$\begin{array}{l}\text { Coping- } \\
\text { strategy }\end{array}$} & Problem-focused coping & 3 & 713 & 0.49 & $0.26-0.67$ & 3.87 & $<0.001$ & 0.072 & 51.86 & 94.2 & $<0.001$ \\
\hline & Intentional rumination & 3 & 811 & 0.54 & $0.44-0.62$ & 9.08 & $<0.001$ & 0.014 & 13.27 & 77.4 & 0.004 \\
\hline & Total & 6 & 1,524 & 0.52 & $0.37-0.65$ & 6.82 & $<0.001$ & 0.012 & 71.49 & 93.0 & $<0.001$ \\
\hline $\begin{array}{l}\text { Traumatic- } \\
\text { experience }\end{array}$ & PTSD & 6 & 3,166 & 0.23 & $0.13-0.32$ & 4.53 & $<0.001$ & 0.012 & 27.41 & 81.8 & $<0.001$ \\
\hline
\end{tabular}

$\mathrm{K}$, number of studies; Cl, confidence interval; PTG, post-traumatic growth; PTSD, post-traumatic stress disorder. 
to 0.62$), z=9.08, p<0.001$, showing significant relationship. Combining problem-focused coping and Intentional rumination, the effect size was $r=0.52$ (95\% CI $=0.39$ to 0.63 ), $z=6.82 p<0.001$, showing significant relationship between Coping-strategy and post-traumatic growth.

\section{Trauma experience-PTSD}

PTSD was analyzed with trauma experience. The effect size between PTSD traumatic growth was $\mathrm{r}=0.23$ (95\% $\mathrm{CI}=0.13$ to 0.32 ), $\mathrm{z}=4.53$, $p<0.001$, showing significant relationship between PTSD and post-traumatic growth (Table 2).

\section{Heterogeneity}

Considering heterogeneity respect to post-traumatic growth, heterogeneity of internal factors was tau ${ }^{2}=0.006, Q=14.72, \mathrm{I}^{2}=59.2 \%, p=0.023$, and external factors was $\operatorname{tau}^{2}=0.042, \mathrm{Q}=39.57, \mathrm{I}^{2}=92.4 \%, p=0.001$. Heterogeneity of coping mechanism was $\operatorname{tau}^{2}=0.011, \mathrm{Q}=24.2, \mathrm{I}^{2}=75.2 \%$, $p<0.001$ and the coping-strategy was $\operatorname{tau}^{2}=0.045, \mathrm{Q}=71.49, \mathrm{I}^{2}=91.6 \%$, $p<0.001$. Heterogeneity of Traumatic-experience was $\operatorname{tau}^{2}=0.012, \mathrm{Q}=$ $27.41, \mathrm{I}^{2}=81.8 \%, p<0.001$. Overall, there was heterogeneity among papers related to post-traumatic growth, hence we decided to determine if there is any publication bias.

\section{Publication bias}

With heterogeneity existing between selected papers, we analyzed whether publication bias was the cause using funnel plot analysis and the Egger's reaction test. Internal factors had no bias with intercept $=-2.868(95 \% \mathrm{CI}=-7.18$ to 1.44$) p<0.244$ and external factors had none with intercept $=-15.755(95 \% \mathrm{CI}=-33.40$ to 1.89$) p<0.329$. Coping mechanisms had no bias with intercept $=-0.997(95 \% \mathrm{CI}=-9.82$ to 7.82$)$ $p<0.835$ and coping-strategy had none with intercept $=-15.755(95 \%$ $\mathrm{CI}=-33.40$ to 1.89$) p<0.329$. Traumatic experience had no bias with intercept $=-2.76(95 \% \mathrm{CI}=-6.29$ to 0.77$) p<0.193$ (Figures $3-7)$.

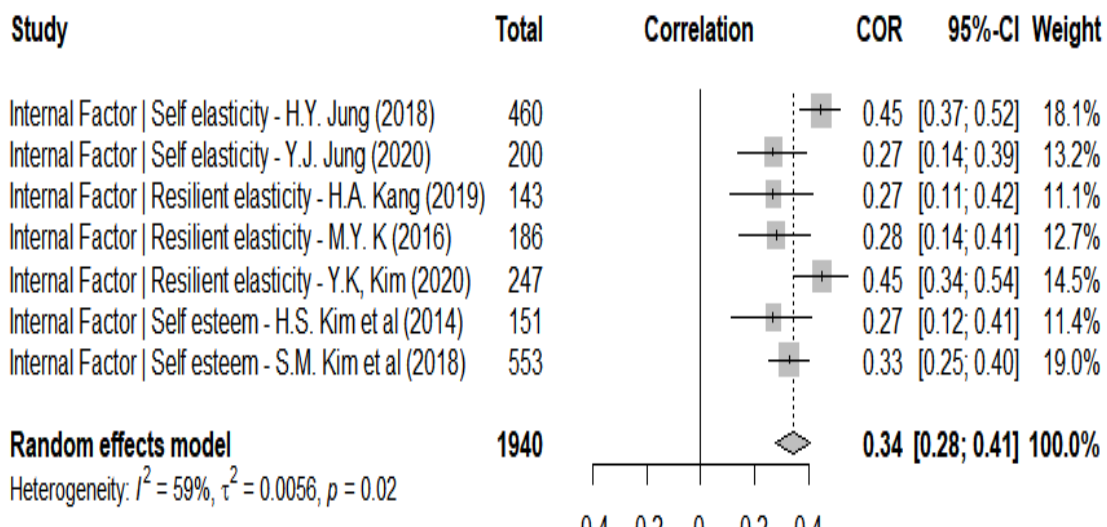

$\begin{array}{ccccc}-0.4 & -0.2 & 0 & 0.2 & 0.4\end{array}$

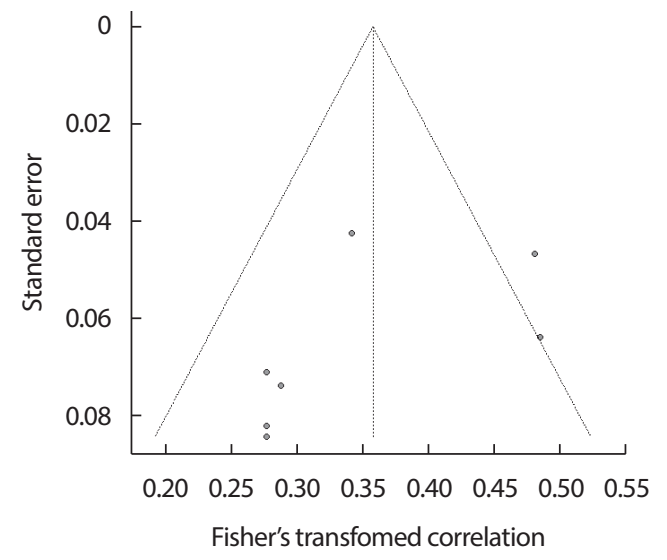

Figure 3. Internal factor: forest plot \& funnel plot. $\mathrm{COR}$, crude odds ratios; $\mathrm{Cl}$, confidence interval.
Study

External Factor|Sense of Calling - H.Y. Jung (2018) 460 External Factor | Career calling- M.J. Kim (2020) 197

Random effects model

992 External Factor | Sense of Calling - N.Y. Lee (2019) 335 Heterogeneity: $I^{2}=93 \%, \tau^{2}=0.0420, p<0.01$
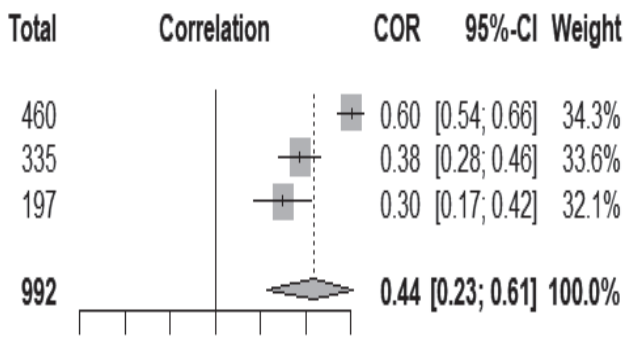

$0.60[0.54 ; 0.66] \quad 34.3 \%$

$0.38[0.28,0.46] \quad 33.6 \%$

$0.30[0.17 ; 0.42] \quad 32.1 \%$

$0.44[0.23 ; 0.61] 100.0 \%$

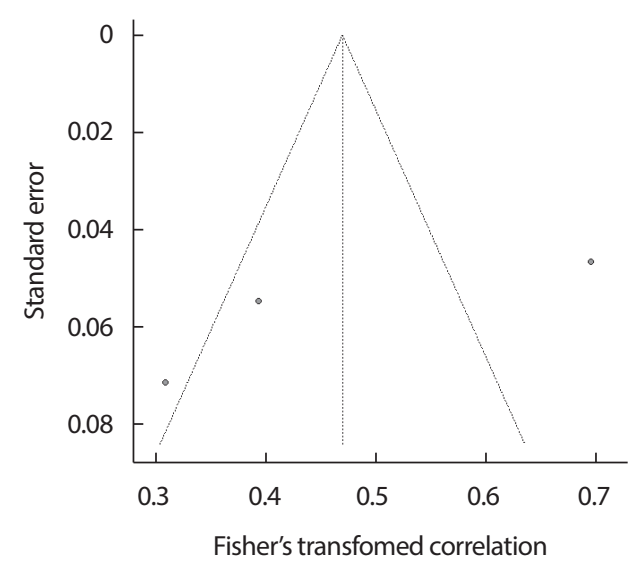

Figure 4. External factor: forest plot \& funnel plot. COR, crude odds ratios; $\mathrm{Cl}$, confidence interval. 

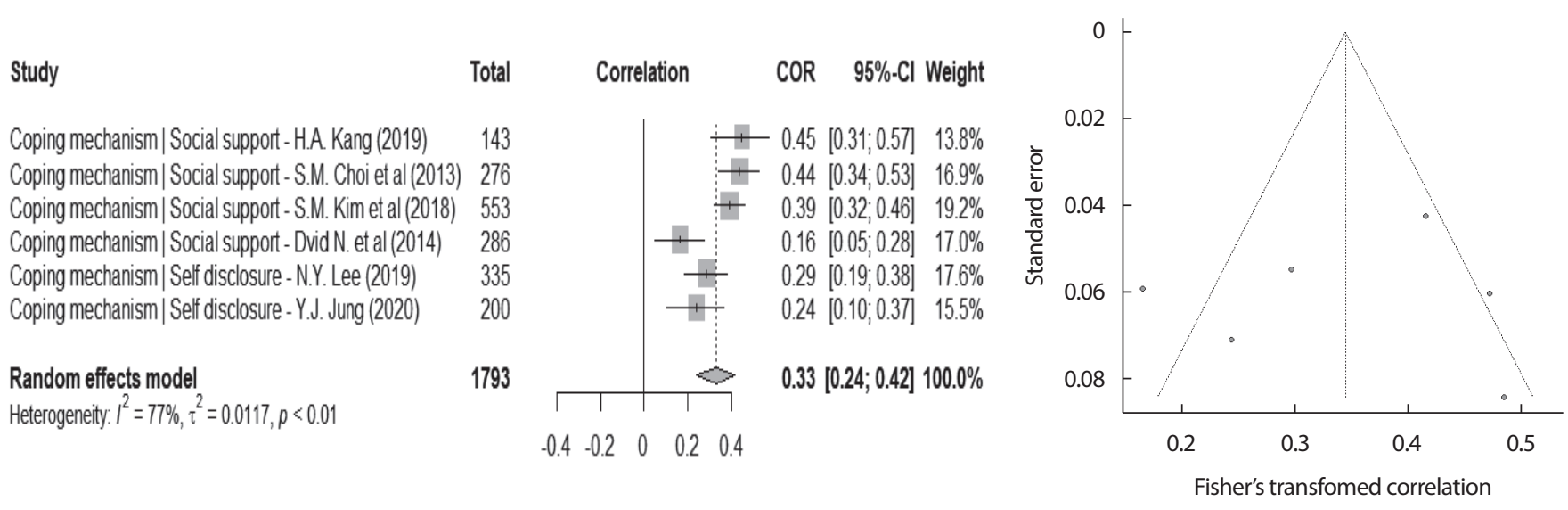

Figure 5. Coping mechanism: forest plot \& funnel plot. COR, crude odds ratios; $\mathrm{Cl}$, confidence interval.
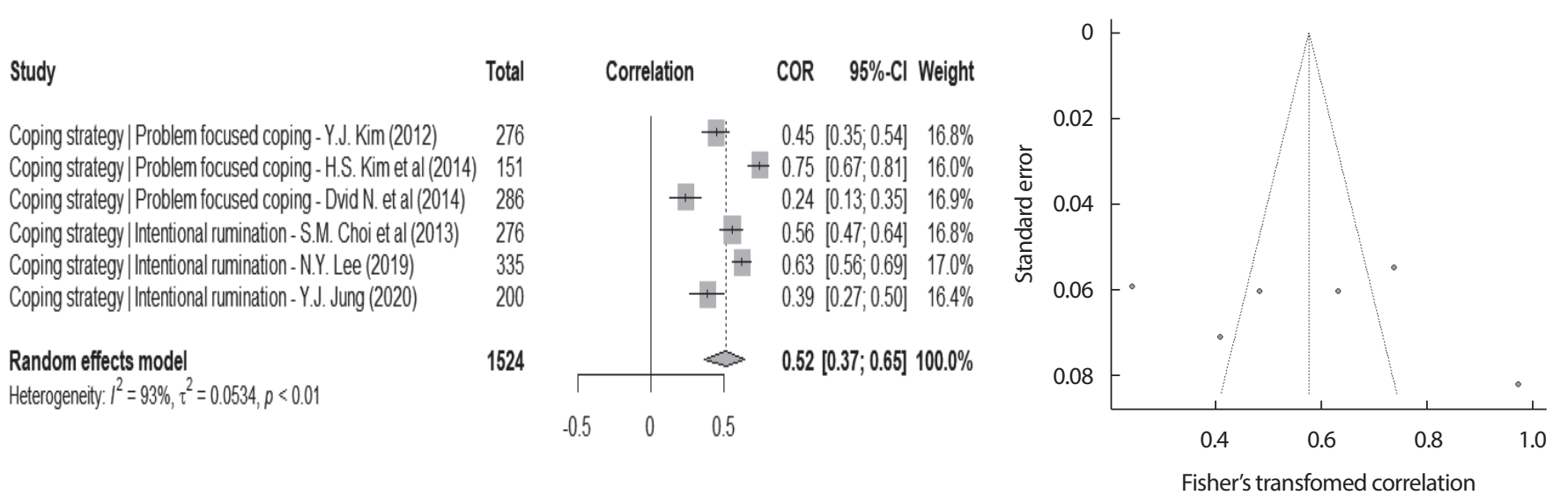

Figure 6. Coping strategy: forest plot \& funnel plot. COR, crude odds ratios; $\mathrm{Cl}$, confidence interval.
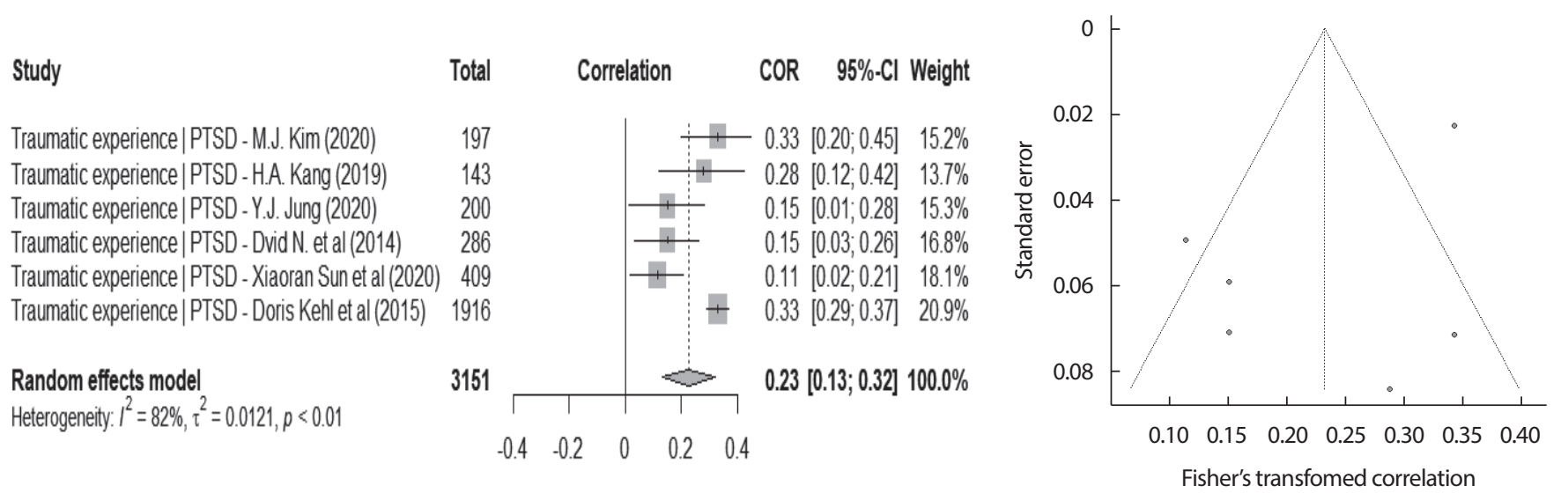

Figure 7. Traumatic experience: forest plot \& funnel plot. $\mathrm{COR}$, crude odds ratios; $\mathrm{Cl}$, confidence interval.

\section{DISCUSSION}

The present study attempted to identify factors related to post-traumatic growth of fire officials in the papers. A total of 14 papers were se- lected to identify the factors, systematic paper studies were conducted, and meta-analysis were conducted to determine the effect size of the correlation coefficient of individual factors.

In order to identify the factors affecting post-traumatic growth of fire 
officials, we classified it into internal-factor, external-factor, Copingmechanism, Coping-strategy, and Traumatic-experience. Firstly internalfactors showed that the effect size was greater in order of self-elasticity, Resilient elasticity, and Self-esteem, and higher the self-elasticity, higher the resiliency, better the post-traumatic growth. A paper on post-traumatic growth [23], claims individual's characteristics before the traumatic event experience, which are individual's personality factors, is an important factor on beginning of the post-traumatic growth. We identified Self-elasticity, Resilient Elasticity, and Self-esteem as factors affecting post-traumatic growth, and preceding studies discuss higher the personality factors, more likely they affect cognitive processing, leading to a better awareness of positive emotions and a change in perception promoting post-traumatic growth. These results suggest that regularly implementing various training programs that could improve self-elasticity, resilient elasticity and self-esteem are identified as internal factors of post-traumatic growth, developing various arbitration programs that could promote post-traumatic growth rather than stress, and applying counseling-techniques should be conducted at a national level.

The external-factor of individuals affecting post-traumatic growth had a greater effect size in order of Sense of Calling and Career Calling, and higher the Sense of Calling, higher the Career Calling, the better the post-traumatic growth experience. Preceding study [24], discusses people with low professional carrier calling tend to experience more PTSD. Another prior study [25] also discusses higher the Sense of Calling and Career Calling, sub-factors of professional carrier calling, clearer the selfclarity and more satisfied the work and life. Limitation of preceding post-traumatic growth models were emphasizing cognitive factors of the individual too much that it is necessary to explore variables containing characteristics of each study group [26]. Fire officials experience a variety of traumatic experiences due to the 24-hour unexpected and unpredictable working environment, and stress and pressures from these could lead to exhaustion and PTSD. In the present study, Sense of Calling and Career Calling have been identified as factors affecting post-traumatic growth of fire officials, and the development of these sub-factors of professional carrier calling could affect by enlarging job satisfaction and strengthening the organization's culture and solidarity. Therefore, it is deemed necessary for further research to explore various factors that may imply the professional specialties of these fire officials approaching more practical and diversely.

Coping-mechanism affecting post-traumatic growth had a greater ef- fect size in order of social support and self-exposure, and the more social support and self-exposure they are, the better they experience post-traumatic growth. In the previous study [27], social support was considered a major factor, and effective for psychological adaptation by suppressing negative emotions and buffering pain after traumatic experience. Meanwhile, Self-disclosure also considered an important factor, a person with proper self-disclosure did it properly could see experience more objectively with better cognitive understanding than a person who did not [28]. According to these results, social support and self-disclosure are pain-control buffers and coping-mechanisms promoting post-traumatic growth. It is necessary to pay attention to the activation of various programs, such as social networks formation and the sharing of self-help groups, that can properly utilize the self-disclosure and social support of fire officials. In addition, nurses need to apply various counseling techniques enabling positive transition in emotional states by appropriately utilizing social support and self-disclosure, and need to provide basic data for the development of arbitration programs for post-traumatic growth.

Coping-strategy affecting post-traumatic growth had a greater effect size in order of Intentional rumination and Problem-focused coping, and Intentional rumination was identified as the most influential factor among all. Post-traumatic growth model 5 discusses humans in posttraumatic stress become more goal-oriented and experience rumination to renew cognitive schema addressing these negative feelings. The appropriate Intentional rumination is likely to experience post-traumatic growth by positively perceiving the meaning of trauma events [29]. Meanwhile, a previous study [30] stated that with problem-focused coping are properly exercised as coping-strategy, one might experiences positive emotions and better control negative emotional responses. This suggests that the use of coping strategy like problem-focused coping allows rapid recovery of the psychological balance and better experience of post-traumatic growth [31]. Therefore, it is necessary to develop and utilize various coping-strategy programs for fire officials to overcome trauma. Utilizing these programs, community mental health care providers will need to play a role in providing proper guidance and education to each fire-fighting agency and ensuring continuity through links with mental health centers.

\section{Limitation}

The limitations of the present study were: first, there were few factors 
needed to be analyzed with control effects due to the high heterogeneity among the papers, but failed with small number of selected papers. Second, factors related to post-traumatic growth targeted specific fire officials, so care needs to be taken in interpreting the overall result. Third, additional repetitive research considering various factors is needed as there were difficulties in securing paper including various factors in meta-analysis of post-traumatic growth of fire officials. Lastly, egger's test showed no publication bias, but it did not show symmetry in the tunnel plot, so it would not be possible to exclude publication bias. Although there were such limitations, the present study was meaningful in identifying meta-analysis and presenting trends in factors. Subsequent research is needed to supplement these limitations in the future, and empirical research needs to be carried out repeatedly by securing various relevant factors to improve the mental health of fire officials need to work in an urgent environment.

\section{CONCLUSIONS}

The present study analyzed post-traumatic growth related factors in fire officials through systematic literature review and meta-analysis, and founded significant factors in post-traumatic growth factors: self-elasticity, resilient elasticity, self-esteem as internal factor, sense of calling, career calling as external-factor, and intentional rumination, and problem-focused coping as coping-mechanism, social support and self-disclosure as coping-strategy and lastly PTSD as traumatic experience. In particular, intentional rumination showed the greatest effect size among all factors, and strategies and measures promoting intentional rumination to fire officials should be sought.

Therefore, the present study seeks to provide the basis for the development of mental nursing arbitration programs accelerating and enhancing post-traumatic growth.

\section{ORCID}

\author{
Myung-Gwan Kim https://orcid.org/0000-0002-6649-4715 \\ Seung-Woo Han ～https://orcid.org/0000-0001-9144-3285
}

\section{REFERENCES}

1. Kim W, Bae M, Chang SJ, Yoon JH, Jeong DY, Hyun DS, et al. Effect of burnout on post-traumatic stress disorder symptoms among firefighters in Korea: data from the Firefighter Research on Enhancement of Safety \& Health (FRESH). J Prev Med Public Health 2019;52(6) 345-354 (Korean). DOI: 10.3961/jpmph.19.116

2. World Health Organization. Evidence-based recommendations for other significant emotional and medical unexplained somatic complaints in non-specialized health settings. Geneva, WHO: 2019.

3. Seligman M, Csikzentmihalyi M. Positive psychology: an introduction. Am Psychol 2000;55(1):5-14. DOI: 10.1037/0003-066X.55.1.5

4. Husson O, Zebrack B, Block R, Embry L, Aguilar C, Hayes-Lattin B, et al. Posttraumatic growth and well-being among adolescents and young adults (AYAs) with cancer: a longitudinal study. Support Care Cancer 2017;25(9):2881-2890. DOI: 10.1007/s00520-017-3707-7

5. Calhoun LG, Tedeschi RG. The foundation of posttraumatic growth: an expanded framework. Handbook of posttraumatic growth: research and practice. Mahwah, NY: Lawrence Erlbaum Associates; 2006.

6. Tedeschi RG, Calhoun LG. The posttraumatic growth inventory: measuring the positive legacy of trauma. J Trauma Stress 1996;9(3):455-471. DOI: $10.1007 / \mathrm{BF} 02103658$

7. Guo J, Liu C, Kong D, Solomon P, Fu M. The relationship between PTSD and suicidality among Wenchuan earthquake survivors: the role of PTG and social support. J Affect Disord 2018;235:90-95. DOI: 10. 1016/j.jad.2018.04.030

8. Brooks M, Graham-Kevan N, Robinson S, Lowe M. Trauma characteristics and post-traumatic growth: the mediating role of avoidance coping, intrusive thoughts, and social support. Psychol Trauma 2019; 11(2):232-238. DOI: 10.1037/tra0000372

9. Huang Q, Zhang Q, An Y, Xu W. The relationship between dispositional mindfulness and PTSD/PTG among firefighters: the mediating role of emotion regulation. Pers Individ Dif 2019;151:109492. DOI: 10.1016/ j.paid.2019.07.002

10. Pérez-San-Gregorio MÁ, Martín-Rodríguez A, Borda-Mas M, Avargues-Navarro ML, Pérez-Bernal J, Conrad R, et al. Post-traumatic growth and its relationship to quality of life up to 9 years after liver transplantation: a cross-sectional study in Spain. BMJ Open 2017;7(9): e017455. DOI: 10.1136/bmjopen-2017-017455

11. Seiler A, Jenewein J. Resilience in cancer patients. Front Psychiatry 2019;10:208. DOI: 10.3389/fpsyt.2019.00208

12. Nakayama N, Mori N, Ishimaru S, Ohyama W, Yuza Y, Kaneko T, et al. Factors associated with posttraumatic growth among parents of 
children with cancer. Psychooncology 2017;26(9):1369-1375. DOI: 10.1002/pon.4307

13. Cohen J. Statistical power analysis for the behavioral sciences. 2 nd ed. Hillsdale, NJ: Erlbaum; 1988.

14. Borenstein M, Hedges LV, Higgins PT, Rothstein HR. Introduction to meta-analysis. Chichester, UK: John Wiley \& Sons, Ltd.; 2009.

15. Higgins J, Green S. Cochrane handbook for systematic review of interventions. Chichester, UK: Wiley-Blackwell; 2011.

16. Viechtbauer W. Hypothesis tests for population heterogeneity in metaanalysis. Br J Math Stat Psychol 2007;60(1):29-60. DOI: 10.1348/0007 11005X64042

17. Duval S, Tweedie R. Trim and fill: a simple funnel-plot-based method of testing and adjusting for publication bias in meta-analysis. Biometrics 2000;56(2):455-463. DOI: DOI: 10.1111/j.0006-341x.2000.00455.x

18. Song SH, Kim KH, Lee HS, Park JH. Reliability and validity of a Korean version of the posttraumatic growth inventory. Korean J Health Psychol 2009;14(1):193-214 (Korean). DOI : 10.17315/kjhp.2009.14. 1.012

19. Cann A, Calhoun LG, Tedeschi RG, Solomon DT. Posttraumatic growth and depreciation as independent experiences and predictors of wellbeing. J Loss Trauma 2010;15(3):151-166. DOI: 10.1080/15325020903375826

20. Zhou X, Wu X, An Y, Chen J. The roles of rumination and social support in the associations between core belief challenge and post-traumatic growth among adolescent survivors after the Wenchuan earthquake. Acta Psychologica Sinica 2014;46(10):1509-1520. DOI: 10.3724/ SP.J.1041.2014.01509

21. Sattler DN, De Alvarado AMG, De Castro NB, Male RV, Zetino AM, Vega R. El Salvador earthquakes: relationships among acute stress disorder symptoms, depression, traumatic event exposure, and resource loss. J Trauma Stress 2006;19(6):879-893. DOI: 10.1002/jts.20174
22. Cohen J. Statistical power analysis for the behavioral science. Hillsdale, NJ: L. Erlbaum Associates; 1988.

23. Tedeschi RG, Calhoun LG. Posttraumatic growth: conceptual foundations and empirical evidence. Psychol Inquir 2004;15(1):1-18. DOI: 10.1207/s15327965pli1501_01

24. Strauser DR, Lustig DC, Cogdal PA, Uruk AÇ. Trauma symptoms: relationship with career thoughts, vocational identity, and developmental work personality. Career Dev Q 2006;54(4):346-360. DOI: 10.1002/ j.2161-0045.2006.tb00199.x

25. Davidson JC, Caddell DP. Religion and the meaning of work. J Sci Study Relig 1994:33(2);135-147. DOI: 10.2307/1386600

26. Zoellner T, Maercker A. Posttraumatic growth in clinical psychology-a critical review and introduction of a two component model. Clin Psychol Rev 2006;26(5):626-653. DOI: 10.1016/j.cpr.2006.01.008

27. Carpenter KM, Fowler JM, Maxwell GL, Andersen BL. Direct and buffering effects of social support among gynecologic cancer survivors. Ann Behav Med 2010;39(1):79-90. DOI: 10.1007/s12160-010-9160-1

28. Jeon YJ, Bae JK. The effects of self-disclosure, social support and intentional rumination on posttraumatic growth. J Human Underst Couns 2013;34(2):215-228 (Korean).

29. Tedeschi RG, Calhoun LG. Posttraumatic growth: conceptual foundations and empirical evidence. Psychol Inquir 2004;15(1):1-18. DOI: 10.1207/s15327965pli1501_01

30. Han SE, Choi ES. The effects of self-esteem and problem focused coping on post-traumatic growth among police officers. Korean J Occup Health Nurs 2016;25(3):141-147 (Korean). DOI: 10.5807/kjohn.2016. 25.3.141

31. Madey SF, Jilek L. Attachment style and dissolution of romantic relationships: Breaking up is hard to do, or is it?. Individ Differ Res 2012; 10(4):202-210. 


\section{국문초록}

\section{소방공무원의 외상 후 성장 관련요인에 대한 체계적 문헌고찰 및 메타분석 김명관 ${ }^{1}$ 한승우 ${ }^{2}$}

1경북대학교 보건대학원 연구원, ${ }^{2}$ 경일대학교 응급구조학과 교수

목적: 본 연구는 소방공무원의 외상 후 성장에 관련된 요인들을 분석하기 위하여 선행논문들을 중심으로 한 체계적 문헌고찰 및 메타 분석 연구이다.

방법: 최종 선정한 14편의 논문은 오픈 소스 통계 소프트웨어인 R (3.6.0)프로그램을 사용하여 상관계수를 활용한 효과크기 메타분석 을 실시하였다. 4 개의 국외 검색엔진과 4 개의 국내 검색엔진으로 시행하였다. 국외 검색엔진으로는 EMBASE, CINAHL, PubMed, Cochrane Library를 통해 검색하였다. 반면 한국 검색엔진으로는 KISS, RISS, NDSL, KMbase를 사용하여 문헌검색을 하였다.

결과: 연구결과 내적요인의 자아탄력성과 외상 후 성장 간의 효과크기는 $r=0.37$, 회복탄력성의 효과크기는 $r=0.34$, 자존감의 효과크기 는 $r=0.32$ 로 나타났다. 외적요인에서 소명의식과 외상 후 성장 간의 효과크기는 $r=0.50$, 직업소명의 효과크기는 $r=0.25$ 로 나타났다. 대 처기전의 사회적 지지와 외상 후 성장 간의 효과크기는 $r=0.36$, 자기노출의 효과크기는 $r=0.20$ 이었다. 대처전략의 문제중심대처와 외상 후 성장 간의 효과크기는 $r=0.49$, 의도적 반추의 효과크기는 $r=0.54$ 로 나타났다. 마지막으로 외상 후 스트레스 장애와 외상 후 성장 간 의 효과크기는 $r=0.23$ 으로 나타났으며 의도적 반추는 외상 후 성장에 가장 크게 효과크기가 나타났다.

결론: 한국 소방공무원의 외상 후 성장에 영향을 미치는 관련요인으로 내적요인, 외적요인, 대처기전, 대처전략, 외상 경험에서 영향을 미치는 변인으로 확인되었다. 그 중 의도적 반추는 가장 큰 효과크기를 나타내었다. 따라서 의도적 반추를 촉진할 수 있는 전략을 개발 하고 본 연구를 바탕으로 정신간호 중재 프로그램에 기초자료를 제공하고자 한다.

주제어: 외상성, 성장, 메타분석, 소방공무원, 체계적 문헌고찰 